\title{
REI DE RAMOS E REI DE OURO: PROTÓTIPOS DO HERÓI ABSURDO
}

\section{Enaura Quixabeira Rosa e Silva Universidade Federal de Alagoas \\ Sheila Diab Maluf \\ Universidade Federal de Alagoas}

\begin{abstract}
A obra literária é um verdadeiro milagre. Existe, vive e atua sobre nós, enriquecendo extraordinariamente a nossa vida, oferecendo-nos momentos de deleite e de descida às profundezas abissais do ser e, apesar disso, é apenas uma formação ontologicamente heterogênea que, no sentido da autonomia de ser, corresponde a um nada.
\end{abstract}

Roman Ingarden

\section{Origens do jogo do bicho}

Em 1888, o Barão de Drummond inventa o jogo do bicho. Pouco a pouco, ele ganha o gosto popular, existindo, hoje, em praticamente todas as cidades brasileiras e passando mesmo a fazer parte do folclore nacional. Nasce da necessidade de arrecadar fundos para a preservação de um zoológico, no bairro de Vila Isabel, no Rio de Janeiro. Em 1892, percebe-se que, de gesto comunitário por motivos ecológicos, evolui para atividade contraventora, pois os que compravam ingressos para o zoológico sequer entravam no parque. Apenas aguardavam a hora do sorteio dos prêmios, transformando, dessa forma, a atividade beneficente em um jogo de azar. Hoje, constitui-se um poder paralelo na vida político-social e econômica de nossas metrópoles, instrumento de corrupção até mesmo da polícia como ordem instituída.

Exercendo o poder econômico em decorrência da exploração do jogo ilegal, tolerado pela polícia graças à propina, o banqueiro do jogo do bicho, popularmente chamado de bicheiro, por mais que cause sucesso nos salões da sociedade será sempre um "pobre homem rico". 
Com muito dinheiro, mas pouca instrução e nenhum traquejo, vive em dois mundos antagônicos sem posição segura em nenhum deles.

\section{A figura do bicheiro na vida e na ficção}

A figura do bicheiro, carregada de dualismo e ambigüidade, oscila entre o bem e o mal. Exerce uma profissão clandestina, usa do poder de vida e morte na comunidade em que vive, entretanto atua "paternalisticamente", financiando estudo e lazer, escolas de samba e educação, reunindo em si mesmo o "pai" e o contraventor. Seu nome aparece com o mesmo destaque nas crônicas social e policial e transita nas altas rodas dos socialites e dos que vivem na marginalidade.

Ficcionalmente, na dramaturgia brasileira, duas peças representam essa figura controvertida: Boca de Ouro, de Nelson Rodrigues (1912-1980) e O rei de Ramos, de Dias Gomes (19221999). A primeira, uma tragédia carioca em três atos, escrita em 1959 , que estréia em 20 de janeiro de 1961. A segunda, uma comédia musical em dezoito quadros, que inaugura o novo Teatro João Caetano em 11 março de 1979, cujo trabalho de escritura foi iniciado em 1975 a pedido de Flávio Rangel e concluído em 1977.' Os protagonistas das referidas peças, o Boca de Ouro e Arlindo Miranda, o famigerado Mirandão Coração-de-Mãe, nascidos da mais profunda miséria material e psicológica, vivem na riqueza e na ostentação e ao morrer enterram-se quase como indigentes.

A personagem Nicolino Pagano, conhecido como Brilhantina, estabelece uma relação de contraste com a personagem do bicheiro Mirandão. Todos os três bicheiros, os protagonistas Boca de Ouro, Mirandão Coração-de-Mãe e Brilhantina, antagonista deste último, são de origem humilde, foram rejeitados por suas mães, ignorados socialmente na infância e o passado se lhes apresenta como uma zona obscura de medo e perplexidade.

Boca de Ouro foi um menino pobre, órfão de pai e de mãe. Carrega na alma o peso de ter nascido em uma "pia de gafieira". Chega a lançar grunhidos, segundo a rubrica, quando conta o fato às grã-finas:

Cf. em GOMES, A. Dias. O rei de Ramos. 2. ed. Rio de Janeiro: Bertrand Brasil, 1987. Apresentação do autor, p. 9-10. 
Minha mãe era gorda, tão gorda, que não se notava a barriga da gravidez. No nono mês, foi dançar nos "Imperadores da Floresta". Lá pulou, cantou, pintou o caneco. De repente, sentiu um troço, um puxo...[...] Minha mãe foi à toalete das senhoras. Então eu nasci. Minha mãe me apanha ${ }^{2}$ e me enfiou na pia. Depois abriu a bica em cima de mim e voltou para o salão. (p. 302)

Esse fato faz com que conserve em seu íntimo um sentimento de inferioridade e de humilhação, originando um sentimento de vingança, uma vontade de humilhar, todas as vezes que alguém menciona a "pia de gafieira".

Também oriundo dos bolsões de miséria, Mirandão Coração-deMãe se fez por si, sem ajuda de ninguém. Abandonado pela mãe, Marcelina, com um mês de nascido, foi criado pela avó que não tinha dinheiro nem para o feijão nem para o leite. Quando espicaçado por Brilhantina, recusa-se a falar do passado, demonstrando claramente sua irritação: "Não gosto de falar nisso. E esse assunto não faz parte da nossa pauta" (p. 63).

Nessa mesma perspectiva, Brilhantina - filho de crioula e calabrês - se reconhece de personalidade difícil quando diz que é "carne de pescoço". Perfuma-se o tempo todo, "porque nasceu e se criou no mangue e no alagado da Favela Varginha, cheirando e comendo merda" (p. 30) e lá ficou até os quinze anos. Afirma que a fedentina nunca lhe saiu do nariz, entretanto contra-argumenta que "fedor por fedor, o do mundo é bem maior" (p. 30).

Banqueiros do bicho identificam-se facilmente como pessoas de personalidades controvertidas, oscilantes entre o bem e o mal, o luxo e o lixo, e as três personagens estudadas também não fogem à regra.

\section{Bicheiros: personagens de dupla face}

Boca de Ouro amalgama sensualidade, astúcia e crueldade, transmitindo uma sensação de vitalidade quase ostentatória. Ocupa um lugar cobiçado, peça-chave da contravenção em Madureira.

Acontece uma quebra da correspondência dos tempos verbais que optamos por não corrigir, considerando que não tínhamos outra edição da obra para conferirmos o texto do autor. 
É implacável com tudo e com todos. Segundo a didascália, institui-se como uma figura "que vai aos poucos entrando para a mitologia suburbana [...] Agora é que, com audácia e imaginação, começa a exterminar seus adversários" (p. 261).

A explicação do apelido de Boca de Ouro surge logo na primeira cena quando ao contracenar com o dentista este diz: "Meu amigo, está de parabéns! [...] nunca vi, palavra de honra, uma boca tão perfeita!" (p. 261). A personalidade do protagonista revela-se quando ele propõe ao profissional que substitua seus dentes, ditos perfeitos, por uma dentadura de ouro. Enquanto o dentista argumenta que não se usa dentadura de ouro, vai sentindo os seus bolsos serem recheados de dinheiro, seguindo-se de uma última tentativa de demonstração de escrúpulos quando exclama: "O senhor está me desacatando", no que prontamente Boca responde: "Que conversa é essa doutor? Dinheiro não desacata ninguém!” (p. 263). Pelas frases: "Quero uma boca todinha de ouro!" (p. 263); "Sonhei que morria e que me enterravam num caixão de ouro."; "Doutor, vou juntar os vinte milhões e quando eu fechar o paletó, vou meter um caixão de ouro..." (p. 264), infere-se a ambição e a necessidade de ostentação compulsiva de Boca.

Contudo, não se trata apenas de ostentação. Estamos diante do poder de um forte simbolismo. Motivações mais fortes podem se esconder sob o desejo de possuir uma boca de ouro. A região bucal permite ao ser humano contatar, pelo mecanismo da sucção, com a primeira fonte de prazer: o seio materno. À personagem foi negada essa experiência o que poderia conduzi-lo, de forma compulsiva e inconsciente, a compensar essa perda na busca de outra forma de satisfação.

A idéia quase obsessiva de enterrar-se em um caixão de ouro também remete ao simbolismo dos objetos que servem para conter ou guardar que, segundo Cirlot (1984, p.134), parece aludir ao inconsciente ou ao próprio corpo materno. Na impossibilidade da posse do corpo da mãe, Boca de Ouro almeja poder comprar, pelo toque de Midas, o seu simulacro. Seria, então, o dinheiro, o objeto que Ihe proporcionaria esse prazer. Boca de Ouro, excremento da mãe, pretende transmudar fezes em ouro, trocando o berço que nunca teve pelo sonho de um esquife de ouro.

Boca de Ouro anseia por poder e prazer. Convém ressaltar sua reação de deslumbramento quando Maria Luísa, uma das grã-finas, 
que o visita, diz: "Boca! Sabe que essa história de caixão de ouro parece coisa de um deus asteca [...]" (p.300). Depois, em um diálogo com a mesma personagem, Boca reitera: "Pensando bem, eu sou meio deus. Quantas vidas eu já tirei? Quando eu furo um cara, eu sinto um troço meio diferente, sei lá, [...]". A rubrica indica o tom dessa fala como de euforia (p. 336). Euforia de poder dispor da vida e da morte? A sensação que experimenta seria o prazer de matar?

Não menos ambicioso que seu colega de Madureira, Mirandão Coração-de-Mãe vangloria-se: "Hoje posso comprar todo o subúrbio de Ramos, se quiser, com a Estrada de Ferro Leopoldina e tudo", e quando decide dar uma festa de aniversário para sua filha, quer que fique "nos anais e menstruais da História" (p. 41). Para isso, compra trezentos litros de uísque escocês de um contrabandista "honesto", com 20 anos de profissão. Mirandão resolve dar de brinde o que sobrar, pois, segundo sua mulher Cida, "isso dá pra embebedar Ramos, Olaria e Bonsucesso" (p. 41).

Alardeia, ainda, que mandou colocar três mil lâmpadas em volta da quadra da Escola de Samba, onde a festa se realiza, em uma nítida necessidade de pompa, de exibição. Acrescente-se a tudo isso sua crença ilimitada no poder do dinheiro, pois pensa em casar sua filha com um príncipe italiano. E, quando ela pergunta assustada: "um príncipe?!" (p. 53), o bicheiro responde sem o menor pudor: "Por que não? Compro um, se você quiser" (p. 54).

Essa personagem carismática irradia simpatia, sendo caracterizada por seu ar paternal de "ditador menor", todavia revela-se um "ferrenho moralista".

Parece carregar sempre nas costas um grande fardo, imensa responsabilidade, como arcanjo cruel e protetor. Sua obediência quase religiosa à "ética profissional" não é um traço de cinismo ou hipocrisia em seu caráter, mas uma noção particular e exótica de dignidade em que ele acredita sinceramente. (p. 21-22).

Interessante destacar essa didascália em que o binarismo entre bem e mal se evidencia pela expressão arcanjo cruel e protetor. 
O substantivo arcanjo, do grego archangelos, significa "anjo-chefe". 3 Pouco antes do texto citado, há na rubrica a indicação de que Mirandão veste-se "todo de branco" (p. 21). A carga simbólica do branco, para Cirlot, está associada ao estado celeste, logo, relacionada ao mensageiro do céu, o arcanjo. Como todo símbolo, contém a dualidade, podendo ser associado ao andrógino, ao ouro ou à divindade (1984, p.124-5). Ora, se Boca e seu caixão de ouro lembram à grã-fina um deus asteca; Mirandão, com seu traje branco, simboliza a tonalidade e a síntese do diferente, do arcanjo que anuncia a salvação ou a condenação, por isso, cruel e protetor. Cruel quando ordena friamente a execução dos que contariam sua vontade, protetor quando paga o enterro e assume a viúva e os órfãos.

O antagonista Brilhantina, ao contrário de seu rival, exibe uma pretensa elegância no trajar. Imbuído de uma obsessão por limpeza, perfuma-se e penteia todo o tempo, "os cabelos reluzentes de brilhantina" (p. 29). Chega ao cúmulo de mandar comprar na farmácia um frasco da melhor água-de-colônia para amenizar sua depressão, em virtude da proibição de banho, quando se encontra no hospital (p.79). Também demonstra, em vários momentos, a compulsividade em ostentar quando, por exemplo, diz à sua mulher Marivalda (por sua vez sempre coberta de uma profusão de jóias, parecendo um carro alegórico) que "a próxima fortaleza do bicho que a gente construir, vou chamar o Niemeyer para fazer o projeto" (p. 57).

Contrapondo-se ao lixo em que nasceram, fazem questão do luxo, sem medir consequiências. Para se tornarem cada vez mais poderosos e distantes dos caminhos que marcaram o início de suas vidas, os protagonistas-bicheiros ostentam sempre, prosseguindo em seu movimento ascensional em busca de mais dinheiro e mais poder.

Seguindo na linha analítica da contravenção e das controvertidas personalidades das personagens estudadas, percebe-se que elas apresentam dupla face. Todos os processos naturais que possuem duas faces contrárias configuram um estado dualista. A integração dessa contradição em um complexo superior cria um

Segundo Mackenzie, na Bíblia o termo só se encontra no capítulo 9 do Livro dos Juizes e na Primeira Carta aos Tessalonicenses, capítulo 4 . versículol 6 na qual Paulo fala do arcanjo que anunciará o Apocalipse. Cf. MACKENZIE, John L. Dicionário Bíblico. 3. ed. Trad. de Álvaro Cunha [et al.] São Paulo: Paulinas, 1983, p. 70. 
sistema binário, que se fundamenta na tensão de uma polaridade. Às vezes, as duas faces são simétricas, possuindo força e extensão equivalentes (o dualismo moral em que o mal se equipara ao bem); mas, em outras, formam pares contrários como o celeste e o infernal.

A personagem Boca de Ouro traduz essa dupla face quando é caracterizado como "o homem que matava com uma mão e dava esmola com a outra" (p. 337) ou que "paga o caixão dos pobres" (p. 291). No que concerne a Mirandão, quando se divulga a notícia de sua morte, ouve-se o coro cantar:

Viva o rei de Ramos

Que nós veneramos

Que nós não cansamos de cantar

Viva o rei dos pobres

Que gastava os cobres

Nas causas nobres do lugar

(p. 16)

E mais adiante, no mesmo canto, o coro continua, patenteando o lado controverso da moeda, a dupla face, o binarismo do bem e do mal:

Os seus desafetos e rivais

Misericordioso não matava

Mandava matar

Efinanciava os funerais

As pobres vilivas consolava

Chegava a chorar

(p. 17)

Boca de Ouro e O rei de Ramos: sínteses do teatro contemporâneo brasileiro

Para Gerd Bornheim, não se pode perder de vista a necessidade de conceder ao texto teatral uma função viva, atual, que consiga realmente atingir o leitor/espectador de hoje, que possa dizer ao homem, de nosso tempo, algo sobre sua situação no mundo (1992, p.23).

Como autores responsáveis pela renovação do teatro brasileiro e pontos de sustentação dessa dramaturgia na contemporaneidade, 
Nelson Rodrigues e Dias Gomes, nas duas peças analisadas, descobrem, reinventam, retrabalham a figura do bicheiro, atualizandoa e nacionalizando-a. Eles lhe outorgam uma significação própria para, através dela, atacar e ridicularizar alguns vícios característicos de nossa época como a corrupção, a exploração do sistema capitalista, hoje travestido de neo-liberalismo, cujo fenômeno dele decorrente, a globalização, metaforiza-se em uma "boca de ouro" descomunal que a tudo e a todos devora.

Dias Gomes, apoiado no gênero comédia musical, encontra a solução perfeita para Mirandão Coração-de-Mãe: uma pretensa morte que lhe permite fugir da ameaça de prisão e participar do jogo maior do mundo capitalista - a formação dos cartéis. A engrenagem de funcionamento fundamenta-se na modernização e na organização de um grupo de empresas do mesmo ramo que ditam os preços e as regras do jogo. Marco, filho de Brilhantina, que estudou economia na Sorbonne, cria o cartel para salvar o jogo do bicho, ameaçado de desaparecer suplantado pelas loterias instituídas pelo governo. A eliminação dos concorrentes far-se-á agora "pela intimidação, pelo suborno, pela política de baixos preços e até mesmo... por meios mais violentos" assevera a personagem Marco (p. 148). Para aprovar a fala do noivo e demonstrar que o "fedor" do mundo é muito maior, Taís, filha de Mirandão, canta:

Como todo cartel que se preza, meu bem

Seguiremos as normas da ética

Muito acima das leis

Muito acima dos reis

Muito acima do bem e do mal

(p. 165)

Nelson Rodrigues retoma o trágico, conferindo-lhe a cor e o tom cariocas por intermédio de sua criatura fictícia, o Boca de Ouro. Ele se afasta da análise política para penetrar fundo na miséria da condição humana, nos meandros dos comportamentos ditados pelas motivações inconscientes. Sua personagem não possui uma família constituída, vive de amores de empréstimo, pagos pelo dinheiro, na ânsia de preencher o enorme vazio do amor materno que desconhece. "Seu rosto é uma máscara feia e cruel", "a máscara astuta, cruel e sensual de um Rasputin suburbano", dizem as rubricas (p. 305 e 337). Seu riso um "ricto de choro", misto de riso soluçante e riso pesado ou 
sórdido. A sua violência irrompe mais do interior de si mesmo, fruto de um dilaceramento interno, de uma dor profunda.

Gerd Bornheim, ao analisar a evolução do conceito de trágico, estabelece a diferença entre sofrimento e dor, citando Kierkegaard:

Na tragédia antiga o sofrimento (das personagens) é mais profundo, e a dor é menor; na tragédia moderna, a dor é maior e o sofrimento menor. $O$ sofrimento sempre contém mais substancialidade que a dor. A dor supõe uma reflexão sobre o sofrimento que este não conhece (1992, p.87).

Bornheim afirma ainda que para Kierkegaard o indivíduo reduzido a si mesmo resulta em um objeto de riso, ao que acrescenta: ridículo e absurdo. Isso porque o herói trágico moderno transmite não mais a sensação da grandeza humana ou da dimensão telúrica ou cósmica à qual o homem trágico do mundo grego pertencia, mas o sem-sentido da existência burguesa.

Boca de Ouro, Mirandão e Brilhantina são generosos e desprezíveis, terríveis e ingênuos, solidários e revoltados, heróis absurdos da condição humana. Vivem esse embate interior, esse dilaceramento entre a cobiça de ganhar cada vez mais dinheiro, o que lhes possibilita as vantagens materiais (parecer) e o desejo de alcançar a função de sujeito na sociedade (ser). O vil metal que subjuga os verdadeiros valores éticos dá-lhes o trono da transgressão e do poder paralelo regido por una ética ao avesso.

Depois de mortos, o rei de Ramos e o rei de Madureira são destronados, entregues à própria sorte. O primeiro, oficialmente reduzido a um número de sepultura e, extra-oficialmente, abrigado em/obrigado a viver na obscuridade/clandestinidade (em Nova Iorque para presidir a International Animal Game Corporation - a multinacional do jogo do bicho - e articular ramificações internacionais do rendoso negócio), mas com a perda completa de sua identidade. O segundo, sepulta-se totalmente desdentado, como se perdendo sua dentadura, sua boca de ouro, fosse-lhe roubado também o próprio ser identitário. 


\section{Referências Bibliográficas}

BORNHEIM, Gerd A. O sentido e a máscara. São Paulo: Perspectiva, 1992.

CIRLOT, Juan-Eduardo. Dicionário de símbolos. Trad. de Rubens Eduardo Ferreira Frias. São Paulo: Editora Moraes, 1984.

GOMES, A. Dias. O rei de Ramos. 2. ed. Rio de Janeiro: Bertrand Brasil, 1987.

INGARDEN, Roman. A obra de arte literária. 2. ed. trad. de Albin E. Beau [et al.]. Prefácio de Maria Manuela Saraiva. Lisboa: Fundação Calouste Gulbenkian, 1979.

MACKENZIE, John L. Dicionário Bíblico. 3. ed. Trad. de Álvaro Cunha [et al.] São Paulo: Paulinas, 1983.

PAVIS, Patrice. Dicionário de teatro. Trad. de J. Guinsburg. São Paulo: Perspectiva, 1999.

RODRIGUES, Nelson. Teatro Completo 3 - Tragédias cariocas. Org. Sábato Magaldi. Rio de Janeiro: Nova Fronteira, 1985. 